\title{
Das ruas ao tapete vermelho: o pañuelazo de Que sea ley como apropriação do espaço estésico
}

\section{From the streets to the red carpet: the pañuelazo of Que sea ley as an appropriation of esthesic space}

Aline $\operatorname{Vaz}^{1}$ 


\section{Resumo}

O objetivo desta pesquisa é analisar o pañuelazo verde, marcha pela descriminalização do aborto realizada no tapete vermelho no Festival de Cannes de 2019, como uma forma de vida que se constitui na apropriação do espaço estésico. Neste contexto, a partir do "agir com", potencializa-se o "agir contra", uma maré verde (progressista) que se manifesta em resposta a uma maré azul (conservadora). Logo, verificando matérias jornalísticas online de distintos países, concluímos que a manifestação de artistas e ativistas é capturada e midiatizada, tornando-se uma experiência estética e comunicacional que transborda o lançamento do filme Que sea ley no Festival de Cannes, como um vetor de experiência estésica que se organiza em torno de movimentos sociais e produtos mediatizados.

Palavras-chave

Que sea ley, pañuelazo verde, Festival de Cannes, experiência estética e estésica.

\section{Abstract}

The research aims to analyze the green pañuelazo, march for the decriminalization of abortion held on the red carpet at the Cannes Film Festival in 2019, as a way of life that constitutes the appropriation of the esthesic space. In this context, from "acting with", the "acting against" is potentiated, a green tide (progressive) that manifests itself in response to a blue tide (conservative). Therefore, checking online journalistic articles from different countries, we conclude that the manifestation of artists and activists is captured and mediatized, becoming an esthetic and communicational experience that exceeds the release of the film Que sea ley at the Cannes Festival, as a vector of esthesic experience that is organized around social movements and mediated products.

\section{Keywords}

Que sea ley, green pañuelazo, Cannes Festival, esthetic and esthesic experience. 


\section{Introdução}

A Campanha Nacional pelo Direito ao Aborto Legal na Argentina, lançada oficialmente em 28 de maio de 2005, no Dia Internacional de Ação pela Saúde das Mulheres, foi idealizada durante o Encontro Nacional de Mulheres de Rosário e Mendoza. Já em 2018, nos meses em que o projeto de lei de interrupção voluntária da gravidez (IVA) transitou no parlamento argentino, a maré verde tomaria conta das ruas. Os pañuelazos verdes, em referência ao lenço - pañuelo, em espanhol - usado pelos participantes das marchas, tornaram-se símbolo da luta pelo aborto legal. O entorno da avenida Callao, entre a avenida Corrientes e a rua Sarmiento, foi ocupado por diversas organizações, como a Ni Una Menos². Apesar da luta popular e da aprovação na Câmara dos Deputados, em 8 de agosto de 2018, o Senado, com 24 a 14 votos, vetaria o projeto de lei de interrupção voluntária da gravidez. Se o Estado continuou punindo mulheres, a luta pelos direitos humanos e democráticos foi incorporada pelas organizações "socorristas", que buscaram dar assistência a elas. Desde então, a chamada maré verde passou a clamar o lema: "Educación sexual para decidir, anticonceptivos para no abortar, aborto legal y gratuito para no morir"3.

A força dos pañuelazos cresceu nos coletivos militantes, e os desdobramentos comunicacionais foram muitos, inclusive no cinema, o que veremos em nosso corpus, com a produção do documentário Que sea ley (Juan Solanas, 2019), filmado no calor das manifestações dos pañuelos verdes, desde a sanção dos deputados

"Al calor de esas voces se consolida el Colectivo Ni Una Menos, con sus muchas expresiones regionales, como parte de un movimiento histórico, que tuvo y tiene hitos organizativos fundamentales en las tres décadas de Encuentros Nacionales de Mujeres y en la Campaña Nacional por el Derecho al Aborto legal, seguro y gratuito. Y que también se reconoce en las Madres y Abuelas de Plaza de Mayo, en las mujeres revolucionarias que fueron sus hijas, en los movimientos LGBTIQ, en las que se organizaron en sindicatos y en las piqueteras, en las mujeres migrantes, indígenas y afrodescendientes y en la larga historia de luchas por la ampliación de derechos. Nuestras libertades y capacidades vienen de esa tenacidad que se acumula históricamente. Somos parte de esa historicidad y, a la vez, contemporáneas de un movimiento de mujeres novedoso, potente, popular, transversal, libertario, con mil rostros y miles de entonaciones, que es regional e internacional, a la vez que se inscribe en cada parte del territorio nacional" (CARTA..., 2017). gravidez até a $14^{a}$ semana de gestação. Após este período, o aborto é permitido apenas em casos de risco de vida para a gestante ou quando a concepção é fruto de um estupro. Os protestos analisados neste artigo, que ocorreram no tapete vermelho em Cannes, são anteriores à aprovação do projeto. 
até a rejeição do Senado, em 2018. "'Eu queria fazer um filme honesto para que as pessoas que estão em uma área cinzenta em relação à legalização do aborto possam vê-lo, fazerem suas próprias perguntas e tirarem suas conclusões', disse Solanas em uma conversa com Télam" (JUAN..., 2019, tradução nossa ${ }^{4}$ ).

Este estudo focalizará a análise das manifestações para além da narrativa fílmica que se apresenta em Que sea ley, nas formas como a equipe do filme e ativistas ocuparam o lugar fora da tela do cinema, construindo uma narrativa de protesto, aproveitando a visibilidade de um lançamento internacional, o Festival de Cannes de 2019. Dessa forma, consideramos que as imagens criadas durante as manifestações no festival - objetos em situação e em experiência sensível - e partilhadas pela midiatização da imprensa - objetos dos discursos enunciados - "perseveram apesar de..." (FONTANILLE, 2014, p. 70), construindo formas de vida no espaço estésico do tapete vermelho. Logo, a partir da divulgação do filme, novas expressividades estéticas serão manifestas, não somente pela equipe artística que age e reage corporalmente, mas pela mídia que, ao captar e divulgar o material, constrói efeitos de sentido e politicidades estéticas.

\section{Construção de sentido: vida coletiva e apropriações interativas}

A semiótica - como teoria geral do sentido - considera que, ao passo que os objetos - arranjos de linguagens - nos apresentam o social, suas práticas e usos culturais, com seus sujeitos, suas leis, suas formas de vida, de consumo, de gosto etc., existirão tanto codificados quanto decodificados. É possível considerarmos a teoria semiótica como aquela que articula os significantes a partir de universos poéticos, em um discurso que cria sentidos de coexistência entre o plano da expressão e o plano do conteúdo, possibilitando analisar as crenças, os sentimentos e as atitudes da sociedade posicionada diante de suas linguagens, ou seja, podemos pensar numa teoria da linguagem associada à noção de forma de vida (FONTANILLE, 2014). 
Se o alvo da análise semiótica é o sentido da vida, dos que a vivem e de suas formas de vivê-la nas mutabilidades que as estão constituindo e imprimindo-Ihes qualidades e qualificações que the atribuem um modo de presença sensível no mundo, e, em suas reiterações, um estilo e uma identidade, a semiótica está além dos textos de papel (os da mídia impressa, por exemplo), dos das ondas (do rádio, da televisão, da internet), dos da luz (os da fotografia, pintura) e ocupa-se igualmente da tessitura das práticas sociais, que são vividas ou estão sendo, no fluxo de suas ações e do desenrolar de seus programas narrativos, patêmicos, figurativos, enunciativos. (OLIVEIRA, 2009, p. 5)

Dessa forma, os objetos vão além dos discursos enunciados, aparentemente fechados em si mesmos - produtos acabados como os filmes e livros; podemos nos debruçar sobre os objetos em situação - entrelaçando contexto e apreensão em ato - e os objetos da experiência sensível - acrescendo à abordagem situacional a dimensão estésica em que o sentido se dá entre o sensível e o inteligível na ocorrência em ato5:

manifestações que, pelo contrário, poderíamos considerar abertas, "dinâmicas", ainda por vir, isto é, que não oferecendo o caráter de unidades fechadas, só se deixarão captar em ato. Não são textos (mesmo em sentido amplo), mas interações em curso, práticas, por exemplo sociais (micro ou macro sociais), se fazendo: uma greve que nunca termina, uma crise internacional que ameaça chegar, uma nova moda que se espalha repentinamente, ou, num outro plano, a cena doméstica que, de tanto se repetir, transforma-se num estilo de vida, ou ainda, menos trivial talvez, certa paixão que sentimos nascer em nós ou, ao contrário, que vemos se desfazer no outro. Tais processos, captáveis somente in vivo, gostaríamos também de poder analisá-los - tanto mais que, em vez de sermos suas simples testemunhas (como o espectador de olhar distante diante de sua catedral), somos agora, de maneira direta, partes interessadas no resultado da sua própria maneira de fazer sentido ao se realizarem. (LANDOWSKI, 2001, p. 24-25)

Será o devir que interessará ao sociossemiótico: "não o devir social ou político tomado ao pé da letra, cuja análise pertence a outras disciplinas, mas pelo menos o devir dos regimes de sentido que fazem significar as transformações sociais ou políticas em questão" (LANDOWSKI, 2001, p. 21). 
Tomar, desta maneira, como objeto de análise o devir do sentido é, no fundo, tentar integrar em nossa disciplina - a semiótica - uma dimensão de caráter prospectivo, a exemplo das ciências políticas e econômicas, também vocacionadas a projetar, a partir da análise do aqui agora, as formas possíveis do amanhã. Infelizmente, os quadros conceituais sobre os quais se apoiam as pesquisas dos politólogos e dos economistas nesse domínio não podem nos prestar grande ajuda. Visando objetivar a história do tempo presente (por exemplo, em termos de "globalização" ou de "mundialização") e adotando para isso um ponto de vista externo com relação ao seu objeto, a análise econômica, e mesmo a ciência política, não nos dizem praticamente nada sobre a questão propriamente semiótica que nós nos colocamos: a de saber se - e de compreender como - este tempo presente, que é o nosso, vem (ou não) a ser experimentado pelos sujeitos mesmos que o vivem do seu interior, como fazendo sentido, independentemente daquilo que ele possa parecer significar e anunciar quando interpretado de fora. Uma semiótica prospectiva, buscando responder a esse tipo de interrogações, requer modelos próprios que, em boa parte, ainda estão para ser construídos. (LANDOWSKI, 2001, p. 21)

Nesta perspectiva, os objetos em situação e em experiências sensíveis estarão associados, nos termos de Jacques Fontanille (2014, p. 65), ao conjunto de experiências interativas e de vida coletiva (o viver junto) denominadas "substâncias", que estão associadas a um conjunto de conteúdos axiológicos e sensíveis (normas, valores e paixões) que, por sua vez, é chamado de forma de vida. O "conviver" nada mais é do que uma macroexperiência que pode ser analisada em experiências constituintes. A convivência é a substância da qual emergem as formas de vida humana.

A percepção de estilos de vida como modos de ser e de sentir se consolida dentro da abordagem sociossemiótica: "esses 'estilos' decorrem, portanto, da tipologia e da descrição das interações sociais e dos fenômenos de significação aprendidos sob a perspectiva dessas mesmas interações" (FONTANILLE, 2014, p. 55). As formas de vida advêm de um estilo que é a representação semiótica das culturas por meio de um objeto. O objeto semiótico manifestará o sensível, ele é a expressão enunciada que para 
Fontanille (2014, p. 57) se apresenta como condensação e forma de vida, e pode ganhar novos arranjos e desdobramentos no momento da interpretação. Para o pesquisador, "'representar-se uma forma de vida' é, portanto, uma interpretação de 'representar a linguagem'"' (p. 61).

$\mathrm{Na}$ perspectiva do autor, há uma categoria genérica do ser/estar junto, agir com ou agir contra que poderá originar experiências interacionais esquematizadas em "estilos figurais". Desse modo, destaca-se o seguinte esquema: ser e fazer com > conviver > forma de vida humana. Assim, nossa pesquisa propõe mergulhar na "relação entre o que se passa nas formas de vida e o que já foi compreendido e estabelecido nas práticas" (FONTANILLE, 2014, p. 68). O espaço estésico, compreendido como movimento relacional fluido e ondulante inerente às vicissitudes do habitar compartilhado, ressignificando paisagens anestésicas (FISCHER; VAZ, 2018), efetiva, talvez, "com efeito, a prática de Spinoza que condensa várias dimensões do 'curso de vida' onde perseverar, na verdade, não é somente 'continuar', mas 'continuar contra ou despeito de' algo que impediria de continuar" (FONTANILLE, 2014, p. 70, grifo nosso). Logo, no tapete vermelho, apesar do veto no Senado argentino, que, em 2018, proibiu a interrupção voluntária da gravidez, o pañuelazo verde acabou por provocar interações sensíveis, construindo um espaço estésico e fortalecendo narrativas pela descriminalização do aborto. Neste contexto, portanto, por meio do agir com, potencializa-se o agir contra - há uma presença feminista que se manifesta no tapete vermelho em resposta a uma presença conservadora que insiste em barrar a conquista de direitos para mulheres (Quadro 1): "é um tema, como em geral na política, que divide meu país exatamente em dois, e chamamos isso de a rachadura', conta o cineasta Juan Solanas" (BELINCHÓN, 2019). 


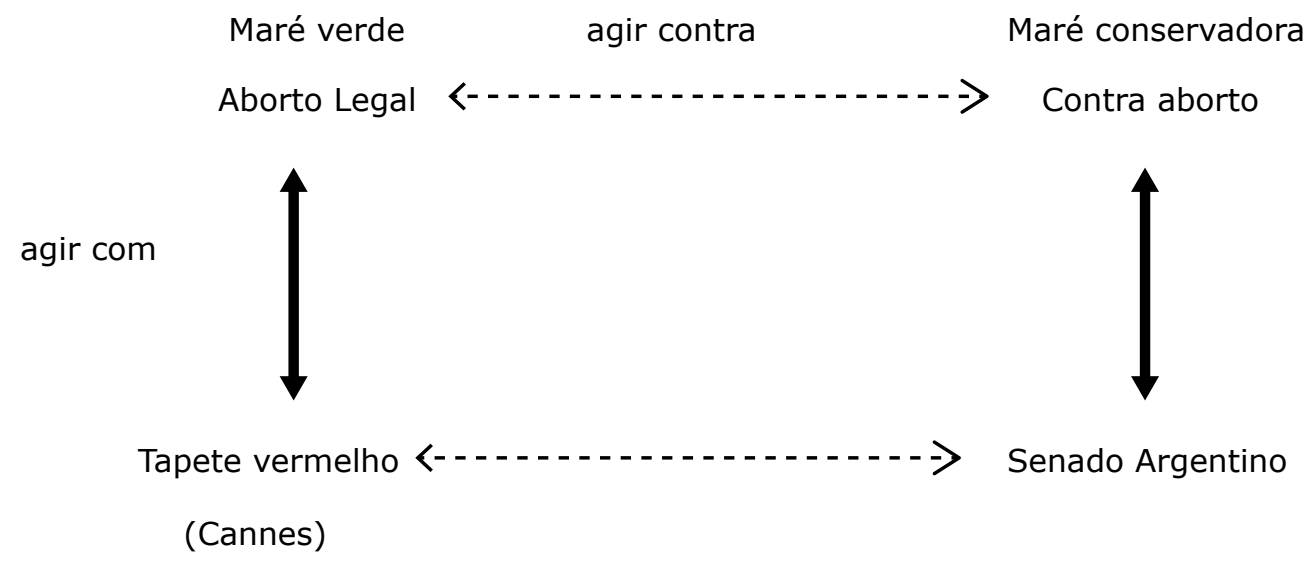

Quadro 1: Esquema de contrários que perseveram

Fonte: elaborado pela autora.

\section{Modos de re-significar: o ato social como processo comunicaciona}

A experiência como fluxo narrativo de um espaço e de um tempo vivenciado como ato social constrói imagens - processos comunicacionais - que potencializam os modos de vida e as possibilidades estésicas. A justaposição entre as experiências estéticas e comunicacionais se articula com a ordem do cotidiano e seus simbólicos acontecimentos sensíveis. Diversas expressividades artísticas, jornalistas, publicitárias, políticas etc. buscam atingir o sensível de determinado público convocando o conceito da experiência. "Podemos falar então dos diversos modos de aparecer do fenômeno estético no âmbito dos objetos (antigos e novos da comunicação). Certamente, cada objeto apresenta demandas e configurações bastante peculiares da relação mais geral entre comunicação, experiência e estética" (LEAL; MENDONÇA; GUIMARÃES, 2010, p. 11). Assim, aquilo que transborda das obras, eventos e situações sociais é algo partilhável que, por meio de estratégias significantes, funciona como experiência estética.

É a transposição de uma ordem sensorial para uma outra que cria as condições suficientes de uma articulação autônoma do significante, cujas figuras se encontram assim distanciadas em relação às figuras do conteúdo. E, pelo contrário, enquanto não houver transposição, a significação do mundo não consegue destacar-se completamente do seu plano fenomenológico. (GREIMAS, 1979, p. 7) 
Nesta dinâmica, realizar ações é importante, mas repercuti-las é indispensável, pois o processo de construção da imagem pública é efetivado ao provocar reações, já que "a experiência em nível estético vai depender da probabilidade - maior ou menor - de ativação relacional (ou de recuperação relacional)" (BRAGA, 2010, p. 79). O pañuelazo verde como performance no tapete vermelho no Festival de Cannes foi amplamente noticiado pela mídia internacional - aqui realizamos um recorte de três meios de comunicação de países distintos cujas matérias estão disponíveis online: El País, no Brasil, BBC News Europe e Clarín, na Argentina.

A matéria do El País (BELINCHÓN, 2019), assinada por Gregorio Belinchón e publicada no dia 23 de maio de 2019, ganha o título: "A luta argentina pelo aborto legal emociona em Cannes" (Figura 1). A manchete da notícia destaca o seguinte trecho: "documentário Que sea ley, de Juan Solanas, inunda o festival de lenços verdes e obtém a solidariedade de artistas e do público". Ao enunciar que "o documentário teria inundado o festival de lenços verdes", revela dois sentidos: 1) a narrativa fílmica teria levado os lenços para tela; e 2) a equipe do filme teria levado os lenços para o tapete vermelho. Além da sala de exibição, a manifestação de artistas e ativistas colocam seus corpos em experiência completa, e estes, ao serem capturados no contexto, encontram-se em partilha sensível com sua audiência (ali convocando a atenção da mídia): "somos nós e o outro, midiatizados no fenômeno do encontro, ou nós midiatizados para o outro no mesmo fenômeno. O outro se encarna para nós pelo suporte técnico disponível na construção da informação, é com esse conjunto que nos relacionamos." (DUARTE, 2010, p. 95). Quando o objeto em situação é midiatizado, o discurso social do filme Que sea ley transborda das salas de exibições do festival de cinema, constituindo-se em uma nova experiência. Logo, teremos primeiramente um objeto de discurso enunciado (o filme Que sea ley exibido durante o Festival de Cannes) e um objeto em situação (o pañuelazo verde no tapete vermelho de Cannes) para constituir outros discursos enunciados pela mídia que, ao noticiar o ato social, amplifica os objetos antecedentes - vinculados ao Festival -, partilhando a experiência com uma audiência que, por meio do suporte técnico da mediatização, terá condições de apreender o sentido do objeto semiótico. 


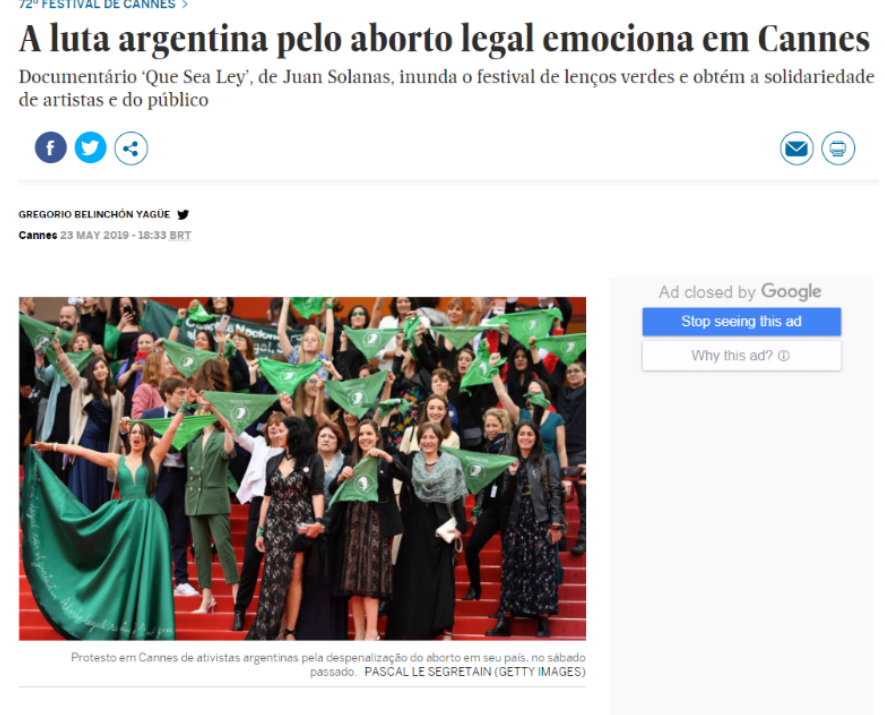

Figura 1: Matéria jornalística - El País.

Fonte: Belinchón (2019)

O texto do El País destaca também quais seriam as presenças físicas que teriam inundado o Festival de Cannes com o pañuelazo (Figura 2): o realizador Juan Solanas e seu pai Pino Solanas ${ }^{6}$, documentarista, senador na Argentina e produtor do filme que aparece na tela no debate final na Câmara, além de 50 ativistas feministas que pagaram elas mesmas os custos da viagem e estadia, como a mãe de Ana María Acevedo, que com 19 anos foi diagnosticada com câncer de mandíbula e teve o tratamento recusado pelos médicos por estar grávida - sem poder realizar o aborto para se tratar contra o câncer, Acevedo faleceu. O verde que encobriu o vermelho de Cannes logo ganhou adeptos do Festival, como as estrelas espanholas de reconhecimento mundial Penélope Cruz e Pedro Almodóvar. A matéria ressalta as palavras de Solanas: "É lógico que encontre eco em todo o mundo, porque este retrocesso é mundial [...]" (BELICHÓN, 2019). O meio de comunicação argentino, o Clarín, na matéria online do dia 17 de maio, assinada por Pablo O. Scholz, além de dar importância também para as personalidades 
argentinas que foram até Cannes para apresentar o filme e protestar (Figura 3), apontou animação com as aproximações institucionais no campo internacional como la fondation des femmes:

Se somaram quarenta atrizes e personalidades da França, como Charlotte Gainbsbourg, e uma vez na sala, cada poltrona terá um lenço verde para que os espectadores possam pegá-lo. E mostrá-lo. [...] Nesta sexta-feira, dia 17, várias atrizes francesas, que por motivos diversos não poderão participar do movimento, assinaram um comunicado de apoio. Entre eles, Marion Cotillard (La vie en rose).

E também na noite de sexta-feira, Solanas foi convidado para um jantar organizado por La Journée $x$ la fondation des femmes. O convite dizia, literalmente que convidava "A todos e todos juntos, de (Agnes) Varda a (Simone) Veil" (pelo Ministro da Saúde francês que foi o promotor do direito ao aborto na França, e que sobreviveu ao Holocausto). (SCHOLZ, 2019, tradução nossa7)

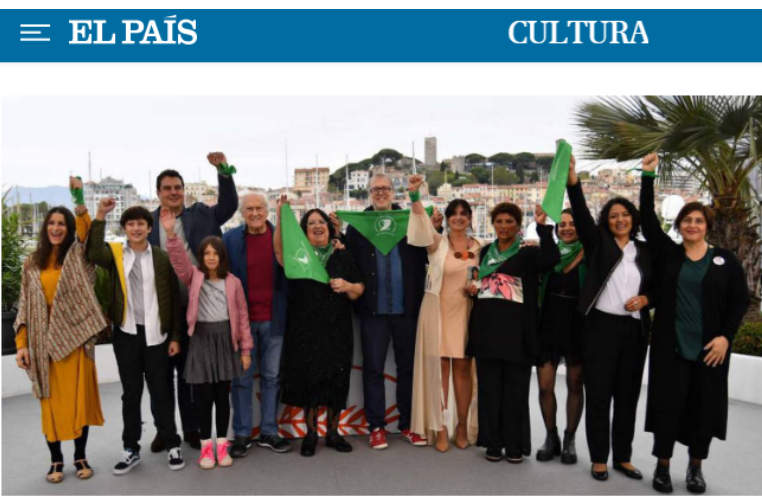

Ativistas e equipe de 'Que Sea Ley' posam diante da imprensa. Entre eles, o senador e cineasta Pinheiro
Solanas (de pulôver vermelho) e o diretor do filme, Juan Solanas (de óculos). ALBERTO PIZZOLI (AFP)

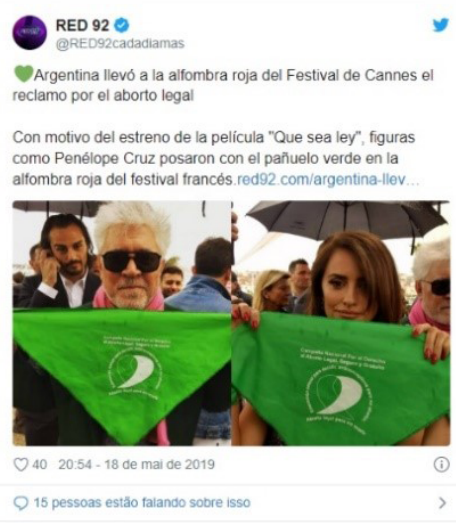

Q 15 pessoas eståo falando sobre isso

Figura 2: Publicações no site do El País e perfil no Instagram Red 92.

Fonte: Belinchón (2019).

No original: "Se sumarán cuarenta actrices y personalidades de Francia, como Charlotte Gainbsbourg, y una vez en la sala, cada butaca tendrá un pañuelo verde para que los espectadores se puedan llevar. Y lucir. [...] Este viernes 17 varias actrices francesas que por diferentes motivos no podrán participar de la movida, firmaron un comunicado en apoyo. Entre ellas, Marion Cotillard (La vie en rose).

Y también en la noche del viernes, Solanas iba invitado a una cena organizada por La Journée $x$ la fondation des femmes. La invitación decía, textualmente que invita "A todos y todas juntos, de (Agnes) Varda a (Simone) Veil" (por la ministra de Salud de Francia que fue la impulsora del derecho al aborto en Francia, y que sobrevivió al Holocausto)". 


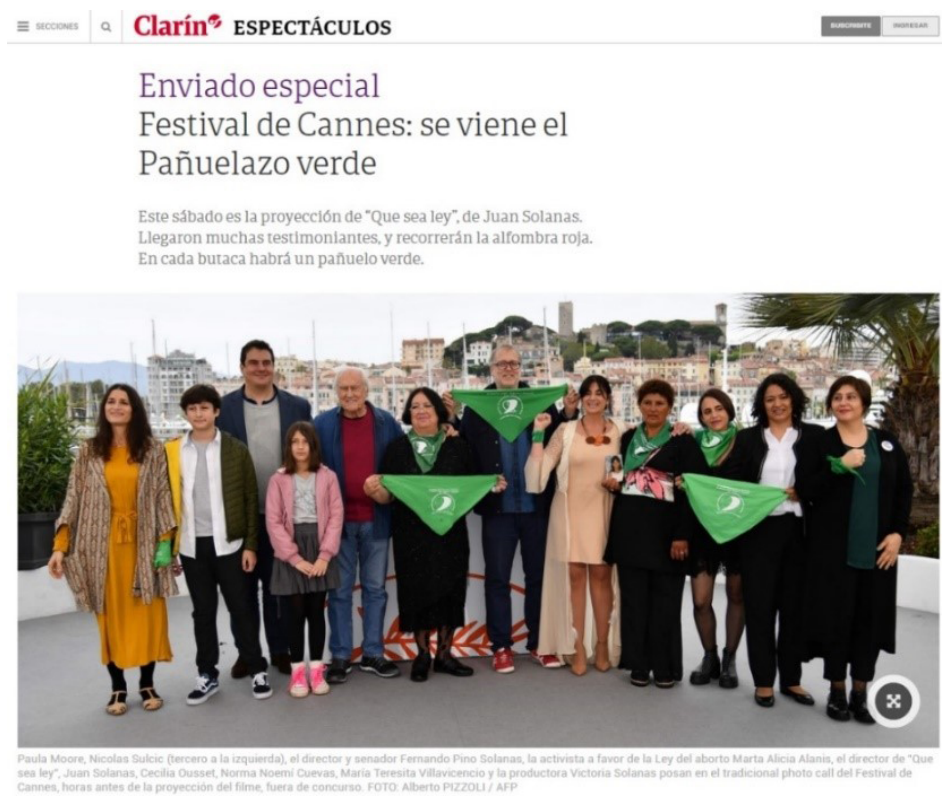

Figura 3: Matéria jornalística - Clarín.

Fonte: Scholz (2019).

Este estar junto - representado tanto pelo imagético das imagens do El País e do Clarín (Figuras 2 e 3) quanto pelos textos que referenciam nominalmente pessoas que aderem ao movimento, como Paula Moore, Nicolas Sulcic, Fernando Pino Solanas, Marta Alicia Alanis, Juan Solanas, Cecilia Ousset, Norma Noemí Cuevas, María Teresita Villavicencio e Victoria Solanas - insere artistas e ativistas em uma causa que inclui o cinema e a luta social pela descriminalização do aborto, levando o pañuelazo das ruas argentinas para o tapete vermelho de Cannes, um lugar que tradicionalmente é passarela do glamour assinado por grandes estilistas, constituindo, deste modo, uma adesão simbólica de todos aqueles que mais tarde seriam afetados pelas estratégias comunicacionais dos meios enunciativos da situação. Retomando as palavras de John Dewey (2010, p. 139), "o que distingue uma experiência como estética é a conversão da resistência e das tensões, de excitações que em si são tentação para a digressão, em um movimento em direção a um desfecho inclusivo e gratificante".

Se o agir com é ressaltado nas matérias do El País e do Clarín, o agir contra é disposto pelo portal online da BBC Europe que, no dia 19 de maio, publicou um 
vídeo de 37 segundos, acompanhado do título "Argentine abortion campaigners take to Cannes red carpet" (Figura 4). O material audiovisual sintetiza o percurso da equipe de artistas e ativistas de Que sea ley com algumas legendas que buscam contextualizar o protesto realizado em Cannes. Nos segundos finais, o vídeo deixa o tapete vermelho e finaliza com imagens de arquivos do lado opositor à maré verde, a maré azul conservadora que lutava contra a legalização do aborto. Enquanto as matérias do El País e do Clarín escolhem enfocar a notícia para a situação vivida no tapete vermelho, a BBC Europe opta por contextualizar as razões que os levaram até ali.
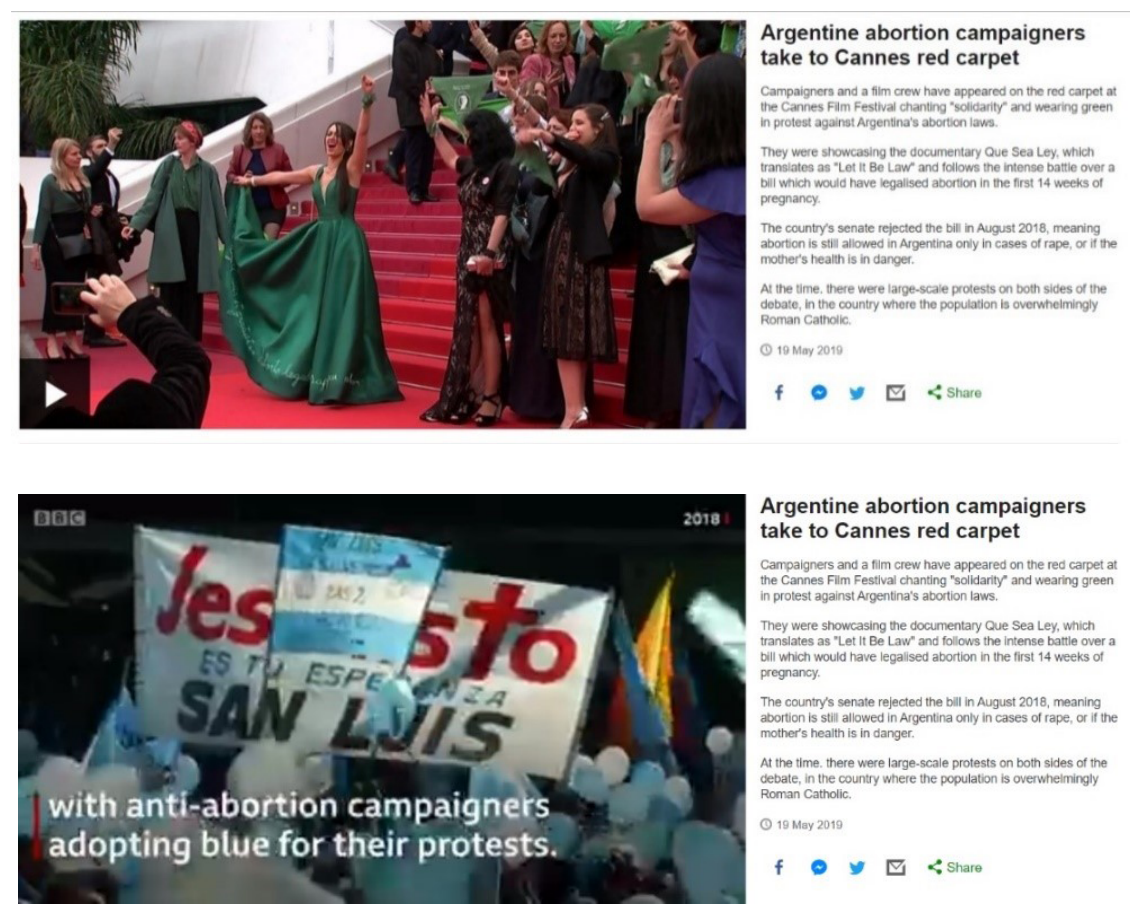

Argentine abortion campaigners take to Cannes red carpet Campaigners and a filim crew have appeared on the red carpet at
the cannes Flim Feestival chanting "solilarity' and wearing green
in protest against Argentinats abortion laws.

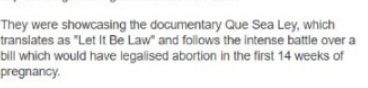

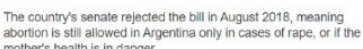
At the time. there were large.scale protests on both sides of the
debate, in the country where the population is overwheimingly
RRoman Canthilic with anti-abortion campaigners 019 May 2019 $f \circ, \nabla<$ Share

Figura 4: Matéria jornalística - BBC Europe.

Fonte: Argentine... (2019).

Por meio da relação corpo e mídia - da transposição do objeto em situação para objetos dos discursos enunciados - se constrói um sentido sociopolítico. Podemos vislumbrar a experiência estética e comunicacional que transborda no lançamento do filme Que sea ley no Festival de Cannes, organizando-se em torno de movimentos sociais e produtos mediatizados, uma situação que ressignifica o tapete vermelho 
em espaço estésico (FISCHER; VAZ, 2018), lugar de compartilhamento de afetos e interações sensíveis, continuando "apesar de" e apropriando-se da passarela de estrelato de Cannes como lugar de resistência do pañuelazo.

\section{Considerações finais}

Este estudo teve como propósito lançar um olhar semiótico para as redes discursivas que se articulam por meio dos objetos dos discursos enunciados, objetos em situação e objetos em experiência sensível. O pañuelazo verde, por meio de um discurso ideológico, apropria-se do tapete vermelho do Festival de Cannes, ressignificando a paisagem potencialmente anestésica do lugar de passagem, em um espaço estésico em que corpos ativos "agem com" "a despeito de".

O protesto frequente nas ruas argentinas tomadas pelo simbólico verde do pañuelos exposto em um festival de alcance internacional expande as possibilidades de compartilhamento. A midiatização promove e permite trocas simbólicas entre os artistas, militantes e a sociedade; ultrapassando o público de cinema, a notícia de jornal "leva a informar, transmitir uma dada mensagem e a construir entendimentos nessa partilha" (DUARTE, 2010, p. 92).

Todos esses modos de dar a ver as politicidades estéticas mantêm viva a pauta pelo aborto legal, seguro e gratuito - que não se encerra com o veto do Senado argentino em 2018. O pañuelazo continuou se manifestando onde e quando possível, seja nas ruas de seu país ou em eventos nacionais e internacionais, e o objeto fílmico é uma estratégia que projeta o discurso político em diversas salas de cinema para variados públicos; além disso, as exibições acabam por conferir outros pañuelazos (Figura 5), formando um ciclo de exibição/ação/midiatização numa narrativa em rede, em que um objeto se enlaça a outro e cria um sentido de devir alicerçado no discurso da resistência pela legalização da interrupção voluntária da gravidez, que tão logo retornou para a discussão parlamentar em 2020. 


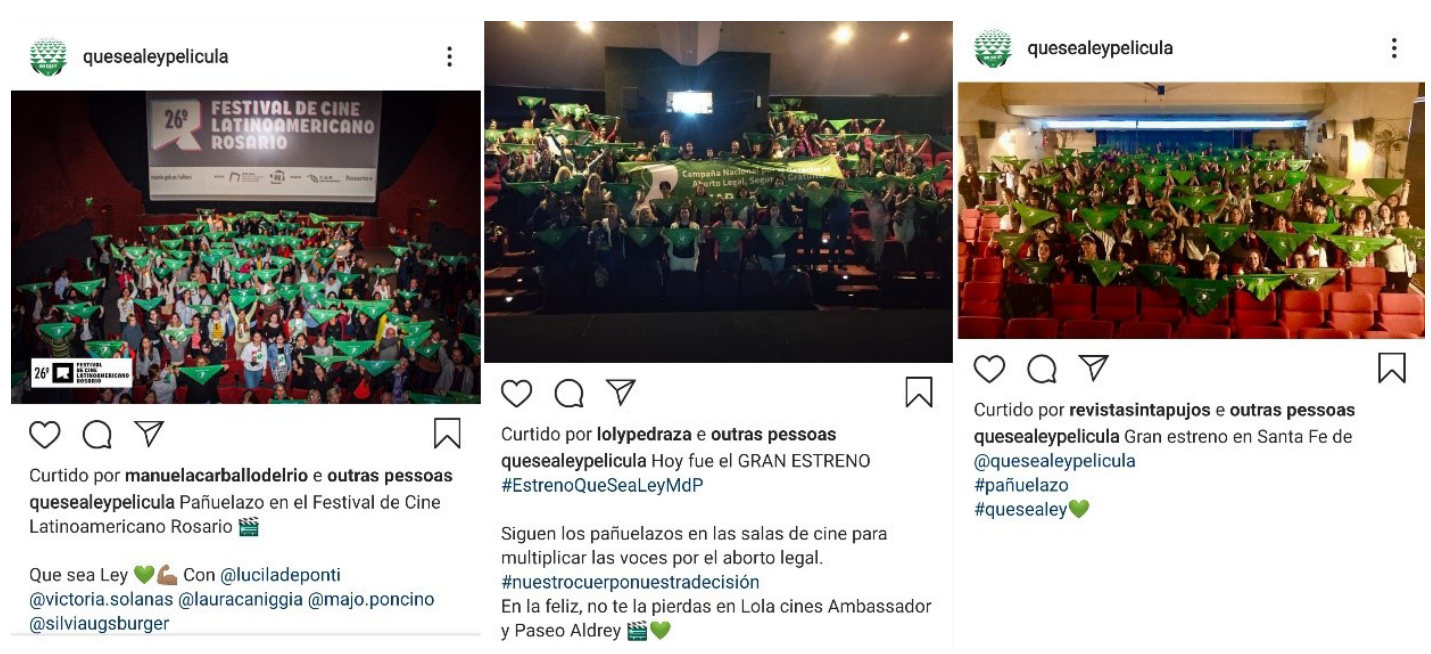

Figura 5: Publicações na rede social Instagram.

Fonte: Instagram @quesealeypelicula.

Vejamos que Alberto Fernández, após eleito presidente da Argentina, em 2019, declarou-se disposto a apoiar a descriminalização do aborto no país, intitulando-se um ativista da causa:

Fernández disse em uma entrevista que gostaria que o debate sobre o aborto "não fosse uma disputa entre progressistas e conservadores, entre revolucionários e retrógrados". O presidente eleito destacou que este é um problema de saúde pública, que deve ser resolvido com este aspecto. (FERNÁNDEZ..., 2019)

Apesar dos esforços do presidente em manter o "conviver junto" unindo progressistas e conservadores, sabemos que houve resistência nas ruas quando o projeto pela legalização do aborto retornou ao debate no Congresso, em 2020. A maior diferença de ação em situação entre as duas marés - a azul conservadora e a verde progressista - é que a azul, parece-nos, passou a ocupar muito menos espaços públicos, e, consequentemente, midiáticos, do que a maré verde ocupou desde que o projeto foi vetado, em 2018. É possível que, julgando-se vitoriosos da batalha, a maré azul não tenha construído tantas estratégias de apropriações de espaços estésicos como verificamos terem sido ocupados pelos pañuelazos 
verdes, inclusive recebendo o apoio do presidente, que teve o projeto de sua autoria aprovado com 38 votos a favor, 29 contra e uma abstenção no Senado.

Importante salientar ainda que, apesar da conquista argentina, os pañuelos verdes não foram recolhidos dos manifestos, pois a luta pelo direito ao aborto legal e gratuito, assim como diversas outras causas feministas, continua a ser pauta na Argentina e por diversos lugares do mundo. Conforme já verificamos, a maré verde é um ato que se desenvolve no conjunto, no agir com e agir contra. Verônica Gago (2020) afirmou a necessidade de um efeito de "ressonância" entre as expressões territorializadas, as quais elaboram uma "espécie de efeito de difusão, de ecos que repercutem e produzem, como efeitos sonoros, amplificações do próprio corpo" (p. 231). Ou seja, a ressonância possibilita "a capacidade de abrir um sentido compartilhado a partir da afetação" como força para a "comoção, e não simplesmente com a recepção de um efeito". A luta local é transnacional e vice-versa - Karina Nohales, porta-voz da coordenação chilena do 8M ressaltou que as reivindicações e conquistas do país vizinho com certeza inspiram a luta feminista:

Estamos inseridas em um ciclo de irrupção de um feminismo de massa que é global e ultrapassa fronteiras; as lutas feministas das mulheres argentinas tiveram um papel fundamental e em grande parte nos contaminaram a ponto de também sairmos às ruas. Esta natureza transfronteiriça torna o triunfo de alguns o triunfo de todos e isso nos aproxima de alcançar amanhã aqui e em toda a América Latina o que a Argentina conquistou. (ATTAB, 2021)

Logo, verificamos a importância das redes discursivas que se articulam nas lutas sociais por meio dos objetos dos discursos enunciados, objetos em situação e objetos em experiência sensível. Quando o objeto em situação é midiatizado, o discurso social constitui-se em uma nova experiência, os discursos enunciados pela mídia amplificam os objetos antecedentes, partilhando a experiência com uma audiência que, por meio do suporte técnico da mediatização, poderá apreender o sentido do objeto semiótico. Há, portanto, uma partilha sensível que constrói e amplifica efeitos de sentidos e formas de vida conjuntas. 


\section{Referências}

ARGENTINE abortion campaigners take to Cannes red carpet. BBC Europe, 19 maio 2019. Disponível em: https://bbc.in/3r5K0kl. Acesso em: 15 fev. 2020.

ATTAB, I. A legalização do aborto na Argentina, uma esperança para a América Latina. Elefante, São Paulo, 25 jan. 2021. Disponível em: https://bit.ly/3CR3rj1. Acesso em: 12 jul. 2021.

BELINCHÓN, G. A luta argentina pelo aborto legal emociona em Cannes. El País, Cannes, 25 maio 2019. Disponível em: https://bit.ly/3DSkzGz. Acesso em: 17 fev. 2020.

BRAGA, J. L. Experiência estética \& mediatização. In: LEAL, B. S.; MENDONÇA, C. C.; GUIMARÃES, C. (org). Entre o sensível e o comunicacional. Belo Horizonte: Autêntica, 2010. p. 73-87.

CARTA orgânica. Ni Una Menos, Buenos Aires, 3 jun. 2017. Disponível em: https:// bit.ly/3FPZNIe. Acesso em: 15 fev. 2020.

DEWEY, J. Arte como experiência. São Paulo: Martins Fontes, 2010.

DUARTE, E. As vertigens estéticas de um campo em configuração. In: LEAL, B. S.; MENDONÇA, C. C.; GUIMARÃES, C. (org). Entre o sensível e o comunicacional. Belo Horizonte: Autêntica, 2010. p. 89-103.

FERNÁNDEZ diz que vai enviar projeto para descriminalizar o aborto na Argentina. O Globo, Rio de Janeiro, 2019. Disponível em: https://glo.bo/3xILnMT. Acesso em: 20 fev. 2020.

FISCHER, S.; VAZ, A. O lugar da morada no cinema de Lucrecia Martel e de Pablo Trapero: paisagens anestésicas ou espaços estésicos? RuMoRes, São Paulo, v. 12, n. 23, p. 21-241, 2018. 
FONTANILLE, J. Quando a vida ganha forma. In: NASCIMENTO, E. M.; ABRIATA, V. L. R. (org.). Formas de vida: rotina e acontecimento. Ribeirão Preto: Coruja, 2014, p. 55-85.

GAGO, V. Potência feminista, ou o desejo de transformar tudo. Tradução de Igor Peres. São Paulo: Elefante, 2020.

GREIMAS, A. J. Condições do mundo natural. In: GREIMAS, A. J.; TORRES, Manuela. Práticas e linguagens gestuais. Lisboa: Veja, 1979.

JUAN Solanas estrena en cine "Que sea ley". Pregon, 2019. Disponível em: https:// bit.ly/3cQX0Sv. Acesso em: 25 nov. 2021.

LANDOWSKI, E. O olhar comprometido. Galáxia, São Paulo, v. 1, n. 2, p. 19-56, 2001.

LEAL, B. S.; MENDONÇA, C. C.; GUIMARÃES, C. Experiência estética e comunicação: a partilha de um programa de pesquisa. In: LEAL, B. S.; MENDONÇA, C. C.; GUIMARÃES, C. (org). Entre o sensível e o comunicacional. Belo Horizonte: Autêntica, 2010. p. 7-15.

OLIVEIRA, A. C. Comunicação e produção semiótica do sentido. In: ENCONTRO DA COMPÓS, 8., 2009, Belo Horizonte. Anais [...]. Belo Horizonte: Compós, 2009.

SCHOLZ, P. O. Festival de Cannes: se viene el Pañuelazo verde. Clarín, Buenos Aires, 17 maio 2019. Disponível em: https://bit.ly/3FSw5SV. Acesso em: 17 fev. 2020. 